\title{
Sorteo y política: \\ ¿de la democracia radical a la democracia deliberativa?*
}

\author{
Sortition and Politics: \\ From Radical to Deliberative Democracy?
}

\begin{abstract}
Resumen: La selección por sorteo ha tenido un renacimiento político, permitiendo la creación de mini-públicos cuyos miembros pueden deliberar en condiciones cercanas a las ideales. ¿Hay un resurgir parcial del ideal de la democracia radical ateniense? El artículo, en primer lugar, resume el papel de la selección por sorteo en Atenas, enfatizando su lógica democrática radical y destacando su singularidad en el mundo pre-moderno. El segundo apartado argumenta que los experimentos actuales suponen una racionalidad política sustancialmente diferente, basada en la muestra representativa, y ofrece una tipología general de los distintos usos del sorteo político. La conclusión expone las condiciones bajo las cuales los mini-públicos deliberativos contemporáneos podrían combinarse con la democracia radical.

Palabras clave: Sorteo, Democracia deliberativa, Democracia radical, muestra representativa, minipúblicos, Atenas.
\end{abstract}

\begin{abstract}
YVES SINTOMER ${ }^{* *}$
\end{abstract}
Fecha de recepción: 30/05/2017. Fecha de aceptación: 27/09/2017.

* Este texto fue escrito en el marco del proyecto I+D: "La recepción de la filosofía grecorromana en la filosofía y las ciencias humanas en Francia y España desde 1980 hasta la actualidad" FFI2014-53792-R (2015-2017) y del proyecto ANR/DFG "(New) Political representative Claims: A Global View (France, Germany, Brazil, China, India)". La traducción al español es obra de Jorge Costa Delgado.

** Profesor de Ciencias Políticas en Université de Paris 8, miembro del Institut Universitaire de France e investigador en el Centre de Recherches Sociologiques et Politiques de Paris, équipe Cultures et Sociétés Urbaines (CRESPPA-CSU).

Líneas de investigación: Teoría de la democracia, Democracia participativa, Democracia deliberativa, Representación política y Sociología alemana. Publicaciones recientes: Sintomer, Yves (2011): Petite histoire de l'expérimentation démocratique. Tirage au sort et politique d'Athènes à nos jours, La Découverte, coll. Poches, París; Sintomer, Yves (2017, en prensa): Le futur de la politique. Post-démocratie, autoritarisme ou révolution démocratique?, La Découverte, París. Contacto: sy@cmb.hu-berlin.de 
El 11 de diciembre de 2004, después de casi 12 meses de deliberación, una Asamblea Ciudadana, seleccionada por sorteo entre la ciudadanía de la Columbia Británica en Canadá, presentó su Informe Final sobre el Cambio Electoral a la Asamblea Legislativa de la provincia. Proponía modificar el sistema electoral introduciendo más proporcionalidad (Waren y Pearse, 2008). Esta recomendación se sometió al conjunto del electorado mediante un referéndum, que se celebró en 2005 junto a las elecciones provinciales (para entrar en vigor, la reforma propuesta tenía que ganar con al menos el $60 \%$ de los votos emitidos en el conjunto de la provincia y con al menos el $50 \%$ de los votos en el $60 \%$ de sus circunscripciones. Aunque fue aprobada en casi todas las circunscripciones, la reforma recibió solamente el 57,69 \% de los votos a nivel provincial; por lo tanto, la ley electoral no se modificó finalmente). Este proceso parece haber sido uno de los más avanzados de entre los miles de usos experimentales similares del sorteo en política durante las últimas tres décadas. Según muchos de los defensores de estos instrumentos deliberativos ${ }^{1}$, la reaparición de esta técnica en política, después de siglos de eclipse, supone el regreso de algunos de los ideales de las democracias antiguas. James Fishkin, quien inventó la encuesta deliberativa, uno de estos nuevos dispositivos de deliberación, la describe como una "solución neo-ateniense" e incluso argumenta que "las debilidades esenciales de la democracia moderna pueden encontrar una respuesta constructiva gracias a las mejoras y ajustes modernos de los dos componentes esenciales de la antigua solución ateniense - muestra aleatoria y deliberación" (Fishkin, 2015). Lyn Carson y Brian Martin (1999, 13-14), dos de los promotores más convincentes del sorteo político, expresan una opinión similar.

Estas experiencias, nacidas bajo el signo de la democracia deliberativa (o, menos frecuentemente, de la democracia participativa), encarnan una crítica a aquellas tradiciones paternalistas que tienden a reducir la democracia al gobierno representativo. Sus defensores suelen considerar que la participación ciudadana es crucial para la buena salud de nuestro sistema político. Reclaman la igualdad política de todos los ciudadanos en el debate público y, en algunos casos, en la toma de decisiones. Creen que la legitimidad democrática está estrechamente ligada a la expansión de la deliberación en el sentido del debate público: una decisión será más legítima, en un sentido normativo y empírico, cuanto más proceda de un debate público animado y bien organizado (Habermas, 1996; Elster, 1998; Manin, 1997; Dryzek, 1990). Esta línea de pensamiento es una respuesta a la creciente desconfianza en el sistema político por parte de la ciudadanía, una significativa tendencia actual al menos en Europa y Norteamérica. En el corpus de la democracia deliberativa, el sorteo juega un papel muy notable (Fishkin, 1997; Dienel, 1997; Waren y Pearse, 2008).

Más allá de las importantes y obvias diferencias entre las democracias modernas y la antigua Atenas, ¿está teniendo lugar un resurgimiento parcial del ideal de la democracia radical ateniense en estas experiencias contemporáneas? Para responder esta pregunta, este artículo resumirá brevemente, en primer lugar, el papel y la importancia de la selección por sorteo en Atenas, destacando su lógica democrática radical. Después, analizará cómo la experiencia ate-

1 La palabra "deliberativo" en el contexto de este artículo se entiende en el sentido inglés — tanto en el lenguaje corriente como en la teoría política - de una discusión de calidad sobre los distintos aspectos de un tema. Una discusión que no implica necesariamente una toma de decisión. De hecho, una característica - y un problemamuy frecuente de los mini-públicos deliberativos es que sean solo consultivos y que estén desligados del proceso real de toma de decisiones. 
niense fue extremadamente singular entre las distintas prácticas de sorteo aleatorio en el mundo pre-moderno. La segunda parte del artículo argumenta que las experiencias actuales basadas en mini-públicos seleccionados aleatoriamente implican una racionalidad política sustancialmente diferente, especialmente porque se fundamentan en la noción de muestra representativa, un concepto desconocido en Atenas. Posteriormente, se examinan los paralelismos y diferencias entre estos dos universos y ambas experiencias históricas se incluyen en una tipología general de los distintos usos de la selección aleatoria en política. La conclusión reúne las principales líneas de esta discusión y expone las condiciones bajo las cuales los mini-públicos deliberativos contemporáneos podrían combinarse con la democracia radical y situarse, de esta manera, con mayor legitimidad, como descendientes del sistema político ateniense.

\section{Atenas: el sorteo como herramienta para la democracia radical}

Más que en otras ciudades griegas, la selección por sorteo fue un procedimiento común en Atenas (Hansen, 1991). El uso de la selección aleatoria se desarrolló pari passu con la propia democracia. La selección por sorteo se usó masivamente durante la edad dorada de la democracia ateniense, en los siglos V y IV a.C. En tiempos de Pericles, se extendió a la mayoría de cargos públicos, mientras el impulso democrático se afianzaba sólidamente a través de la marginación del Areópago, el establecimiento de una remuneración diaria para los miembros del Consejo (bouletai) y los jurados sorteados de los tribunales populares (461 a.C.).

\subsection{El sorteo en el sistema político ateniense}

Condensando dos siglos de tumultuosa historia constitucional, podemos resumir la racionalidad constitucional ateniense de la siguiente manera. Al margen de las formas aristocráticas heredadas de la Época Arcaica, las instituciones atenienses se basaban en una tríada de procedimientos: la asamblea del pueblo, las elecciones y la selección aleatoria. Aristóteles consideraba que las tres se complementaban mutuamente en el establecimiento de la democracia, pero añadió que era principalmente a través de la selección aleatoria de los líderes como se expresaba la naturaleza profundamente democrática de una ciudad. La elección, aunque necesaria para el equilibrio general, encarnaba, al menos en parte, un principio diferente: "Se considera democrático que los cargos deban ser cubiertos por sorteo y oligárquico que deban ser electivos" (Aristóteles, 1962, 168; traducción modificada por el autor). Aristóteles completó el retrato señalando que, en el caso de las elecciones, estas eran oligárquicas si el sufragio estaba limitado en función de la propiedad y democráticas si todos o casi todos los ciudadanos podían participar. Desde su punto de vista, Atenas tenía un "sistema mixto" compuesto por elementos aristocráticos y democráticos.

En efecto, cada ciudadano podía presentarse a la selección por sorteo, de acuerdo al principio de ho boulomenos ("cualquier persona que lo desee"). Esta funcionaba en cuatro grandes tipos de instituciones. En primer lugar, servía para la constitución anual de la Boulé, el principal consejo de la democracia ateniense. Cada uno de los demes geográficos que componían la polis ateniense estaba representado en el Consejo a través de las diez "tribus" (o distritos), que contribuían, cada una, con cincuenta ciudadanos de más de treinta años de 
edad. Esto hacía a la Boulé representativa del conjunto del territorio de Atenas. Los puestos de responsabilidad dentro de la Boulé también se cubrían por sorteo - especialmente el puesto de presidente, que se renovaba cada día al atardecer. Cada presidente podía así afirmar al final de su mandato: " $Y$ Yo fui presidente de Atenas durante veinticuatro horas, pero no más!” (Hansen, 1991).

En segundo lugar, además de la Boulé, la mayoría de las magistraturas (600 de un total de 700) se cubrían por selección aleatoria. Las diez principales eran los arkhontes, seis de los cuales (los thesmosthetai) eran guardianes de la ley y responsables de los tribunales. Los arkhontes se nombraban en dos fases: cada una de las diez "tribus" geográficas seleccionaba diez de sus miembros por sorteo; después, un segundo procedimiento centralizado resultaba en la elección de uno de cada tribu. Las otras magistraturas probablemente se cubrían por un procedimiento centralizado.

Además, todos los jueces se seleccionaban por sorteo. La ciudadanía conllevaba el derecho inalienable a participar en la asamblea y a ser miembro de un jurado (Aristóteles, 1962, III, 2, 1275a). Cada año, se elegían seis mil ciudadanos por sorteo para formar el tribunal (Heliaia), que a veces se reunía en sesión plenaria, pero más frecuentemente se dividía en varios tribunales más pequeños (dikasteria) en función de los asuntos a tratar. Quienes se encargaban de dirigir los tribunales también se seleccionaban por sorteo. Los miembros de los jurados no podían deliberar y solo podían votar después de escuchar a las partes que comparecían ante ellos. A esta escala y con esta frecuencia, la selección por sorteo se convirtió en una actividad rutinaria.

Finalmente, en el siglo IV a.C., una asamblea cuyos miembros (nomothetai) estaban sorteados tenía que aprobar las leyes adoptadas por la asamblea general de los ciudadanos (Ecclesia) antes de su promulgación definitiva.

A este respecto, el kleroterion, la "máquina" para el sorteo mencionada por Aristófanes ya en el 393 a.C. (López-Rabatel, 1991) y diseñada de tal manera que numerosos testigos podían observar su funcionamiento, fue muy importante. Hacía el procedimiento más rápido y sencillo, al mismo tiempo que lo protegía de cualquier intento de manipulación. Los atenienses conocían otras formas de sorteo, con oráculos y dados (Hattler, 2008, 26 y ss.), pero el kleroterion se reservaba exclusivamente para fines judiciales y políticos. El kleroterion, en definitiva, materializó y reforzó el ideal democrático ateniense.

\subsection{El ideal de la democracia radical}

En Atenas, la participación y la deliberación estaban estrechamente ligadas. El debate público que involucraba a todos los ciudadanos estaba inextricablemente vinculado a la ciudad, con diferentes y complejas formas. En la asamblea del pueblo se desarrollaba un debate fundamentalmente contradictorio, en el cual los oradores intentaban convencer a la audiencia: una práctica conceptualizada por Aristóteles como retórica. Sin embargo, el público podía participar activamente. Las prácticas de la Boulé eran, sin duda, más interactivas, ya que se producían discusiones políticas cara a cara en distintos espacios públicos del ágora (Ruzé, 1997; Villacèque, 2013). En los tribunales, por el contrario, se requería a los jurados que formaran su opinión escuchando a las distintas partes, pero sin deliberar, ya que toda discusión entre los miembros del jurado estaba prohibida. 
Aristóteles resumía las características comunes de todas las democracias de la manera siguiente: “(1) Elecciones: todos los ciudadanos son elegibles para todos los cargos; (2) gobierno: todos gobiernan a cada uno y cada uno a todos, por turnos; (3) cargos provistos por sorteo, ya sea todos o, al menos, aquellos que no requieren experiencia o formación; (4) ningún mandato o cargo limitado [...] en función de la propiedad y si existe limitación, es muy moderada; (5) el mismo hombre no ejerce dos veces el mismo cargo, o solamente muy rara vez - con algunas excepciones, especialmente cargos relacionados con la guerra; (6) mandatos cortos para todos los cargos o para tantos como sea posible; (7) jurados elegidos de entre todos los ciudadanos para juzgar todos o la mayoría de los casos y siempre los más importantes o de mayor alcance, como [...] la constitución, investigaciones, contratos entre particulares; (8) la Ecclesia es la autoridad soberana en todo y los magistrados no tienen poder sobre nada, salvo cuestiones menores, o al menos el Consejo es soberano en los asuntos de mayor importancia." (Aristóteles, 1962, IV, 2, 1317-b, p. 237).

Selección por sorteo, rotación de mandatos, igual participación en la vida política, rendición de cuentas de los cargos públicos, el lugar central de la asamblea del pueblo o del consejo, la deliberación en la esfera pública: estas eran las características institucionales que materializaban los ideales de la democracia. Todos los ciudadanos, no solamente las élites, podían vivir en conformidad con la naturaleza del ser humano como zoon politikon, que tenía su origen y alcanzaba su plenitud moral solamente en la comunidad política. La mayoría de las funciones políticas se asignaban durante un período que iba desde unos meses hasta un año completo, y el acoplamiento entre rotación y selección por sorteo era especialmente efectivo para protegerse de la profesionalización de la actividad política y de la monopolización del poder por parte de expertos en un campo propio, separado de la ciudadanía. Desde esta perspectiva, el ideal de la ciudad-estado era, a la vez, político y epistemológico: defendía la libertad de sus miembros en igualdad y sostenía que todos tenían legítimo derecho a participar en la reflexión y acción política, dado que estas no se concebían como actividades especializadas.

La oposición entre demócratas moderados y radicales se centraba en el rol de los líderes electos como personajes diferenciados de la masa de los ciudadanos. Así, en su célebre discurso fúnebre en honor de los soldados de Atenas, Pericles declaraba que aunque todos los ciudadanos eran iguales ante la ley y podían hablar si así lo deseaban, independientemente de sus medios económicos, "nosotros escogemos a nuestros mandatarios de acuerdo a su consideración pública, por lo que los ciudadanos son nombrados por sus méritos, antes que sucediéndose unos a otros por turnos" (Thucydides, The Peloponnesian War, II, 37, cita modificada por el autor). En contraste con este principio meritocrático, Cleón apelaba a la sabiduría del hombre común:

"Deberíamos darnos cuenta... de que la falta de formación combinada con un sano sentido común es más útil que ese tipo de inteligencia cuyo afán de distinción acaba fuera de control, y de que, como norma general, los estados están mejor gobernados por el hombre de la calle que por personas de más sutil inteligencia... el tipo de personas que pretenden parecer más sabias que las leyes. Sin embargo, los otros hombres... están preparados para admitir que las leyes son más sabias que ellos. Tienden 
a criticar menos los argumentos de un orador habilidoso, dejan que sus juicios sobre los asuntos estén guiados por el sentido común, no por un espíritu competitivo. Por eso, sus políticas suelen tener efectos beneficiosos" (Thucydides, The Peloponnesian War, III, 37, cita modificada por el autor).

A pesar de importantes limitaciones, el ideal democrático se correspondía, al menos parcialmente, con lo que en realidad ocurría en la práctica. El estilo de vida ateniense giraba en torno a la actividad política y los ciudadanos participaban sobre una base extremadamente igualitaria, en comparación con otros sistemas conocidos a lo largo de la historia. Durante un período de treinta años, gracias a la selección por sorteo y a la rotación de cargos, entre un cuarto y un tercio de todos los ciudadanos de más de treinta años servirían en el Consejo durante un año y como prytanis, o dirigentes del Consejo, durante un mes. Casi el 70 por ciento de los ciudadanos de más de treinta años fueron bouletai, al menos una vez en sus vidas (Finley, 1991, 73f.; Ruzé, 1997, 380), y una proporción aún más alta fueron seleccionados como jurados, por lo que muy pocos ciudadanos quedaban completamente excluidos si querían participar. Estas instituciones funcionaban como escuelas de democracia, en una sociedad con una cultura cívica muy desarrollada, donde el contacto cara a cara hacía más fácil el control mutuo.

Por supuesto, la ciudad-estado ateniense excluía a las mujeres y a los esclavos de la vida política y usaba su fuerza para someter a las ciudades aliadas. Pese a todo, dentro del relativamente estrecho círculo de ciudadanos, el poder era en gran parte ejercido por el pueblo (en el sentido legal del conjunto de la ciudadanía), antes que solamente por representantes. Como señaló Moses I. Finley, para comprender este sistema tenemos que ir más allá de la ecuación "democracia es igual a elecciones". En gran medida, Atenas se negó a profesionalizar la política, creyendo que era una actividad en la que todos podían y debían participar (Finley, 1991, 70; 1985; Castoriadis, 1986, 282-3).

\subsection{El sorteo adivinatorio y el sorteo distributivo}

Para comprender la innovación radical del sorteo ateniense, debemos contextualizar su práctica. En realidad, el sorteo estaba extendido por todo el mundo Mediterráneo y el Oriente Próximo durante la Antigüedad (Herodotus, Histories, I, 94, 167; II, 32; III, 25, 84-86, 128; IV, 68; VII, 23; Cardano y Grottanelli, 2001). No obstante, durante la Época Arcaica la selección aleatoria estaba imbuida de un significado adivinatorio: lejos de establecer la igualdad entre la gente, kleros (la "suerte del azar", por así decirlo) revelaba el destino (moira en griego) que esperaba a cada individuo. En el pasaje más exhaustivo sobre este tema, la Ilíada demostraba cómo el kleros podía utilizarse para identificar el héroe que se enfrentaría al enemigo en representación de todos los griegos. Usado de modo ritual, este tipo de sorteo cumplía la doble función de reducir los conflictos entre pares y revelar el individuo que había sido previamente escogido por los dioses para enfrentar su destino (Homer, The Iliad; The Odyssey; Guidorizzi, 2001, 41-54; Demont, 2000, 299-325).

El significado del sorteo como medio para la atribución de funciones políticas fue completamente transformado por la difusión de la democracia, que sistematizó el uso de esta práctica en Atenas en el siglo V a.C. A pesar de que el uso de este método iba acompañado de un importante ritual, la selección aleatoria dejó de asociarse a la adivinación y adquirió un 
nuevo significado, decididamente secular. Desde este punto de vista, ninguna otra ciudad en el Próximo Oriente tuvo una evolución similar a la de Atenas y las otras democracias griegas; tampoco los usos que los romanos hicieron de la selección aleatoria fueron similares.

Muchos siglos después, Tomás de Aquino (1270-1271) estableció una distinción entre los usos adivinatorios y seculares del sorteo que más tarde se convertiría en canónica. Aquino observó el creciente uso de la selección aleatoria para nombrar magistrados en las ciudadesestado italianas, que estaban redescubriendo un procedimiento aparentemente desaparecido siglos atrás. En su clasificación, Aquino dio fundamento teológico a la condena de las prácticas adivinatorias basadas en la suerte ("sors divinatoria" o "sortes sanctorum"), que la Iglesia había prohibido desde el Concilio de Vannes en el 462, pero que seguían siendo muy practicadas. El teólogo también defendió la prohibición de procedimientos de selección aleatoria para los cargos de la Iglesia, una prohibición que, de hecho, había sido promulgada por el Papa varias décadas antes (Aquino, 2008).

Con ese fin, Tomás de Aquino identificó tres tipos de sorteo. El primero, al que llamó "distributivo" ("sors divisoria"), se consideraba el más legítimo. Este procedimiento podía utilizarse en asuntos seculares, cuando no estaba claro cómo repartir bienes o distribuir funciones y cargos. Sin embargo, como la Iglesia se había convertido en una institución, estaba prohibido utilizar en ella esta conveniente medida: hacerlo hubiera sido insultar al Espíritu Santo y a la sabiduría que este había conferido a sus clérigos, en particular a sus obispos. Siempre se podía confiar en la jerarquía cuando hubiera desacuerdos. El segundo tipo de sorteo, el "consultivo" ("sors consultatoria"), se permitía también únicamente en los asuntos seculares: consistía en dejar una decisión al azar cuando no estaba claro qué opción tomar después de agotar la capacidad de razonamiento propia. El tercer tipo de sorteo, llamado "adivinatorio" ("sors divinatoria"), implicaba solicitar indebidamente el juicio divino mediante el uso de técnicas adivinatorias. Tomás de Aquino reiteraba su prohibición e incluso la ampliaba, en tanto que el sorteo adivinatorio solo podía suponer un pacto con el Diablo o, en el mejor de los casos, permitía que los demonios intervinieran en los asuntos humanos. La gravedad de los pecados que ello conllevaba dependía del tipo de adivinación practicada.

Esta clasificación sigue siendo, en parte, analíticamente pertinente. Si dejamos a un lado el "sorteo consultivo", que podemos considerar menos fundamental que los otros dos tipos, y lo sustituimos por los muy extendidos juegos de azar, todas las prácticas de sorteo pueden dividirse en tres grupos (Cardano y Grotanelli, 2001). "Sorteo distributivo" (sors divisoria), que consiste en distribuir aleatoriamente bienes, funciones o cargos; cleromancia (sors divinatoria), un tipo específico de adivinación usando el sorteo; y juegos de azar.

Estas tres categorías pueden, a su vez, subdividirse. El sorteo distributivo (sors divisoria) puede comportar distribuir bienes (y diferentes tipos de bienes) o funciones y cargos. La cleromancia (sors divinatoria) puede revelar el destino de alguien o la expresión de una voluntad divina. Las dos cosas no son exactamente la misma: la idea del destino puede referirse a una esfera sobrenatural o a un orden cósmico que no implican la voluntad personal de una deidad y puede perdurar en usos rituales incluso cuando la secularización y la racionalización han desacreditado la creencia en la intervención directa de los dioses. La cleromancia puede además referirse a varias técnicas. Y, finalmente, los juegos de azar pueden dividirse en muchas categorías diferentes, en particular dependiendo de los instrumentos utilizados (cf. figura 1). 
Figura 1: Los usos de la selección aleatoria

\begin{tabular}{|c|c|c|c|c|}
\hline \multicolumn{2}{|c|}{$\begin{array}{l}\text { Distribución de bienes, cargos } \\
\text { y funciones: sorteo distributivo } \\
\text { (sors divisoria) }\end{array}$} & \multicolumn{2}{|c|}{$\begin{array}{l}\text { Cleromancia: sorteo } \\
\text { adivinatorio (sors } \\
\text { divinatoria) }\end{array}$} & Juegos de azar \\
\hline $\begin{array}{l}\text { Distribución } \\
\text { de bienes en } \\
\text { lotes: tierras, } \\
\text { propiedades, } \\
\text { botín, bienes } \\
\text { raíces, servicios } \\
\text { sanitarios escasos, } \\
\text { etc. Distribución } \\
\text { "negativa": } \\
\text { castigos, } \\
\text { reclutamiento } \\
\text { militar, } \\
\text { impuestos, etc. }\end{array}$ & $\begin{array}{l}\text { Distribución } \\
\text { de cargos y } \\
\text { funciones: } \\
\text { políticas, } \\
\text { militares o } \\
\text { religiosas }\end{array}$ & $\begin{array}{l}\text { Revela un } \\
\text { destino }\end{array}$ & $\begin{array}{l}\text { Expresa una } \\
\text { voluntad } \\
\text { divina }\end{array}$ & \multirow[t]{2}{*}{$\begin{array}{c}\text { Juegos de dados o } \\
\text { con huesos (varios } \\
\text { milenios a.C.); } \\
\text { sorteos (China, } \\
200 \text { a.C., Imperio } \\
\text { Romano, siglo XV } \\
\text { d.C en Europa); } \\
\text { juegos de naipes } \\
\text { (China, siglo IX } \\
\text { d.C., Europa, siglo } \\
\text { XIV d.C.); lotería } \\
\text { (Génova, siglo } \\
\text { XVI d.C.), etc. }\end{array}$} \\
\hline \multicolumn{2}{|c|}{$\begin{array}{l}\text { Distribución del poder político, } \\
\text { entendido como propiedad sobre los } \\
\text { gobernados y sus bienes }\end{array}$} & \multicolumn{2}{|c|}{$\begin{array}{c}\text { Extracción de un objeto (sors, } \\
\text { kleros - cleromancia en } \\
\text { sentido estricto), de cartas } \\
\text { (cartomancia), selección } \\
\text { aleatoria de la página de } \\
\text { un libro (bibliomancia); } \\
\text { adivinación usando dados o } \\
\text { astrágalos (astragalomancia), } \\
\text { pequeños bastones } \\
\text { (achilleomancy); quema } \\
\text { de caparazones de tortuga } \\
\text { (cheloniomancy); etc. }\end{array}$} & \\
\hline \multicolumn{4}{|c|}{$\begin{array}{l}\text { Distribución de bienes, funciones y cargos como destino revelado o } \\
\text { expresión de la voluntad de Dios }\end{array}$} & \\
\hline & & \multicolumn{3}{|c|}{$\begin{array}{l}\text { Interpretación de la suerte o la mala fortuna en el } \\
\text { juego como signo del destino o (más raramente) } \\
\text { como voluntad divina }\end{array}$} \\
\hline \multicolumn{5}{|c|}{$\begin{array}{l}\text { Potencial uso de los mismos instrumentos para el sorteo distributivo, la cleromancia y los } \\
\text { juegos de azar, transfiriendo técnicas de un dominio a otro }\end{array}$} \\
\hline
\end{tabular}

Fuente: compilada por el autor. 
Por supuesto, estas distinciones son en buena medida analíticas: en la práctica, los distintos ámbitos se influencian mutuamente y las transferencias son frecuentes. La unidad original del sorteo distributivo (sors divisoria) se derivaba de una visión del poder como una forma de propiedad sobre la gente, los territorios y los bienes muebles. En este sentido, era lógico confundir la distribución de los bienes con la distribución de funciones y cargos (cosa que, sin embargo, ya no ocurría en la Atenas Clásica). Por otra parte, la revelación del destino y la expresión de la voluntad divina tienen a menudo fronteras difusas, especialmente en sociedades donde existe una fuerte creencia en la acción voluntaria de fuerzas sobrenaturales. La idea de que el sentido del sorteo distributivo derivaba de la intervención de Dios o de algún tipo de manifestación sobrenatural estuvo igualmente muy extendida a lo largo de la historia (aunque esta última dimensión había desaparecido casi por completo en la democracia ateniense). Finalmente, las técnicas e instrumentos utilizados para aplicar la selección aleatoria eran a menudo los mismos que aquellos utilizados en los juegos de azar, en la adivinación y en la política; a la inversa, la creación de herramientas específicas como el kleroterion generalmente indicaba la creciente autonomía de un campo respecto a otro y, en particular, la creciente autonomía de la política respecto de la religión.

Mientras que la selección aleatoria era una práctica muy extendida en el antiguo Próximo Oriente, el "sorteo distributivo" de las magistraturas nunca jugó un papel central en la organización política: solamente se usaba esporádicamente, cuando era necesario solventar un problema especialmente difícil, establecer mandatos excepcionales o distribuir poderes entre dioses e individuos, a los que se asignaba así su "suerte" o destino. Al contrario, Atenas y algunas otras ciudades griegas fueron excepcionales, ya que la selección aleatoria de los cargos políticos y judiciales llegó a tener un papel central en el sistema político de la ciudad. Nuestra comparación entre la democracia antigua y la democracia deliberativa contemporánea resulta pertinente en relación a esta modalidad específica de sorteo.

\section{Sorteo y democracia, antigua y moderna}

Desde esta perspectiva, ¿cómo podemos interpretar las referencias modernas a las prácticas atenienses? ¿Y hasta qué punto son estas referencias histórica y teóricamente relevantes?

\subsection{Mini-públicos seleccionados aleatoriamente y Democracia deliberativa}

A principios de los años 70, los jurados ciudadanos (pequeños grupos de ciudadanos elegidos al azar, organizados para transmitir a las autoridades cómo percibía el público determinadas cuestiones) comenzaron a recuperar la selección por sorteo para la política, casi simultáneamente en Alemania y en los Estados Unidos (Dienel, 1997; Crossby, 1975). A finales de los ochenta, las "conferencias de consenso", grupos de quince personas no profesionales seleccionadas aleatoriamente, empezaron a convocarse en Dinamarca para discutir amplias opciones científicas y tecnológicas. Y, en esa misma época, surgió en los Estados Unidos la idea de las encuestas deliberativas aplicadas a determinados asuntos, involucrando a cientos de ciudadanos. Todos estos dispositivos son parte de una tenden- 
cia más amplia que situaba a la participación ciudadana en la democracia en el primer plano. Lo novedoso es que estos dispositivos se basaban en muestras representativas seleccionadas aleatoriamente o, al menos, en una sección razonablemente diversificada de ciudadanos de a pie. Durante las décadas de los noventa y los dos mil, estas herramientas fueron aplicadas en otros países, dando como resultado nuevas y variadas experiencias. La Asamblea Ciudadana de la Columbia Británica se convirtió en una fuente de inspiración para otras regiones. Estos modelos empezaron a combinarse con otros instrumentos (como los presupuestos participativos).

La tendencia se ha incrementado durante la década de 2010. En noviembre de 2009, Islandia, seriamente golpeada por la crisis financiera, creó una asamblea ciudadana compuesta de 950 individuos seleccionados al azar y algunos cientos de personas cualificadas. La tarea de la asamblea consistía en identificar los puntos más importantes para una reforma constitucional. Se repitió el proceso con una nueva asamblea, esta vez completamente sorteada, para después elegir, mediante sufragio universal, una especie de jurado compuesto de veinticinco ciudadanos. Estos debían elaborar una nueva ley fundamental basada en el material producido por la asamblea previa. En mayo de 2015, los ciudadanos irlandeses votaron a favor en un referéndum convocado para decidir sobre una reforma constitucional que legalizaba el matrimonio de personas del mismo sexo, aprobando así un borrador de ley elaborado por una asamblea ciudadana elegida en su mayor parte por sorteo. Las mentalidades están cambiando rápidamente. La idea de recuperar el sorteo para la política se está haciendo cada vez más popular en muchos países.

\subsection{Muestra representativa, representación descriptiva y opinión pública contrafactual}

Hay evidentes diferencias entre Atenas y experiencias como las Asambleas Ciudadanas en la Columbia Británica, Islandia o Irlanda; y aún mayores con respecto a otros dispositivos deliberativos que incluyen la selección aleatoria de ciudadanos. En los países occidentales modernos, casi todos los adultos son ciudadanos de pleno derecho. El equilibrio entre elecciones y sorteo es muy desigual: la técnica de la selección al azar no es habitual ni tampoco forma parte de los procedimientos constitucionales normales. En las demás experiencias, se usa solamente en ocasiones muy concretas, cuando una autoridad pública decide libremente organizar una cámara sorteada. Antes de 2010, las experiencias políticas basadas en el sorteo funcionaban normalmente en los márgenes de la política y la experiencia de la Columbia Británica era más bien la excepción, antes que la norma. Probablemente, hasta 2015, el único ejemplo de una ley que instauraba el sorteo de manera sistemática y obligatoria, al margen del ámbito judicial, fue la Revisión de la Iniciativa Ciudadana (Citizens' Initiative Review) que se aprobó en 2011 en Oregón (el proyecto de ley obligaba a organizar un jurado ciudadano para evaluar las propuestas de las iniciativas ciudadanas antes de someterlas a referéndum) (Knobloch, Gastil y Reitman, 2015).

Otra diferencia crucial, aunque menos evidente, tiene que ver con el significado de la selección aleatoria (Sintomer, 2011a). En Atenas, el sorteo y la rotación acelerada de los cargos permitían a los ciudadanos gobernar y ser gobernados por turnos. Por eso puede hablarse de autogobierno y esa es la razón por la cual, en el pensamiento político clásico, el sorteo se asociaba a la democracia y las elecciones a la aristocracia, un argumento que 
Jacques Rancière (2007) recuperó en la pasada década. El uso contemporáneo de la selección aleatoria es muy diferente. La probabilidad real de ser elegido para una Asamblea Ciudadana o una cámara similar es muy pequeña. La idea consiste, más bien, en utilizar el sorteo para seleccionar un microcosmos de la ciudadanía, un grupo que tenga las mismas características y la misma diversidad que la ciudadanía, pero a menor escala. De esta manera se crearía un "mini-público", que es estadísticamente viable cuando se toma una muestra representativa de la ciudadanía. Un grupo de cientos de ciudadanos seleccionados al azar tiende a ser representativo del pueblo en su conjunto. Un grupo más pequeño de diez a veinte personas, el tamaño más habitual de los jurados ciudadanos, no puede ser verdaderamente representativo, pero incorpora en parte la pluralidad social. Esta "sección razonablemente diversificada de la comunidad (fair cross-section)" ("The Jury Selection and Service Act”, 28 U.S.C., secs 1861-69, citado en Abramson, 2003, 100) tiende, a menor escala, a ser similar al conjunto de la población. Tales grupos encarnan un tipo específico de "representación descriptiva" (Pitkin, 1972), que supone que los representantes políticos tienen que ser sociológicamente semejantes al pueblo que representan.

La noción de muestra representativa resulta familiar para los lectores del siglo XXI, gracias a décadas de uso intensivo de la misma en estadísticas y sondeos de opinión. Por eso parece "bastante racional ver el sorteo como un medio, considerando la representación descriptiva como un fin" (Stone, 2009, 375-397, 390). Sin embargo, la muestra representativa es un invento de finales del siglo XIX. Primero se introdujo en la política con los sondeos de opinión, a mediados del siglo XX, y solo se convirtió en un instrumento para seleccionar jurados judiciales y varios jurados y comités políticos a finales de los sesenta y en los setenta (Abramson, 2003). Puede que no existiera ninguna relación entre la selección al azar y la representación descriptiva en Atenas, ya que la idea de que la selección aleatoria produce estadísticamente una sección representativa de la población no estaba disponible en la época. La suerte no había sido todavía científicamente "domesticada" (Hacking, 1990) en la esfera política. La representación descriptiva fue importante durante la época de las revoluciones francesa y norteamericana. John Adams $(1851,205)$ pudo así escribir que la asamblea legislativa debía ser "una imagen exacta, en miniatura, del conjunto del pueblo". Asimismo, Mirabeau (1789) argumentaba que la asamblea debía ser "para la nación lo que un mapa a escala es para su área física; ya sea en parte o por completo, la copia siempre debe tener las mismas proporciones que el original". Pero como era imposible basarse en la noción de muestra representativa, los promotores de la representación descriptiva ignoraron el sorteo y plantearon otras soluciones técnicas (Sintomer, 2011a). Los Anti-federalistas propusieron pequeños distritos electorales para favorecer a la clase media-baja. Otra solución aconsejaba la representación por separado de diferentes grupos sociales mediante métodos corporativistas - una propuesta demasiado asociada al Antiguo Régimen como para convencer a demócratas radicales. En el siglo XIX, el predominio de facto de las clases superiores entre los representantes frecuentemente llevó a la idea de la representación específica de grupos subordinados y, particularmente, de la clase obrera.

Bernard Manin (1997) fue el primero en preguntarse por qué la selección por sorteo desapareció de la escena política con las revoluciones modernas. Planteó una doble respuesta. Por un lado, los padres fundadores de las repúblicas modernas querían una 
aristocracia electiva antes que una democracia y, por lo tanto, era lógico que rechazaran el sorteo. Por otra parte, la teoría del consentimiento, profundamente enraizada en la concepción moderna de la ley natural, había ganado tanto terreno que parecía difícil legitimar cualquier autoridad política que no fuera formalmente refrendada por los ciudadanos de un Estado. Estos dos argumentos son importantes, pero no nos cuentan toda la historia. En particular, no logran explicar por qué las minorías radicales no reivindicaron el uso de la selección por sorteo en política, incluso cuando hicieron campaña por una representación política entendida como espejo de la sociedad, en la cual el cuerpo de representantes se asemejaría al pueblo en su totalidad.

Para comprender estos desarrollos, deben señalarse otros factores. Tenemos que abandonar el terreno de las "puras" ideas políticas y ver la manera en que se materializan, a través de técnicas de gobierno y otras herramientas y mecanismos. La ausencia de un concepto estadístico de muestra representativa en la época de las revoluciones francesa y americana, cuando la estadística y el cálculo de probabilidades ya estaban bien consolidados, pero no combinados entre ellos, es una razón fundamental por la que la selección política por sorteo desapareció en las democracias modernas, con sus grandes poblaciones y tamaños - también es el motivo por el que aquellos que defendían una concepción descriptiva de la representación tuvieron que elegir forzosamente otras herramientas para acercarse a sus ideales (Sintomer, 2011a). El mero tamaño demográfico y territorial de las repúblicas modernas parecía impedir cualquier consideración seria del sorteo político, ya que este no podía garantizar a todos los ciudadanos gobernar y ser gobernados por turnos y, por tanto, no podía crear un mini-público.

A la inversa, el resurgimiento actual de la selección por sorteo en un creciente número de experiencias también está relacionado con la muestra representativa. La selección aleatoria, tal y como se practica hoy en política, está inseparablemente ligada a este concepto. La deliberación de una sección razonablemente diversificada del pueblo no es lo mismo que el autogobierno popular. Proporciona a todos las mismas oportunidades de ser seleccionados; pero como las probabilidades individuales son muy pequeñas, no garantiza a todos los ciudadanos el acceso a cargos públicos por turnos. En su lugar, mediante un mini-público, proporciona una opinión contrafactual que es representativa de lo que la opinión pública podría ser. Para los demócratas deliberativos contemporáneos, la semejanza estadística entre representantes "descriptivos" y el pueblo es solamente un punto de partida. El mini-público tiene que deliberar y, durante el proceso, cambia de opinión. Comienza así a pensar, en cierto modo, de manera distinta y ese es precisamente el valor añadido de la deliberación. Esto se observa muy claramente cuando leemos a James Fishkin $(1997,162)$ :

"Tomemos una muestra aleatoria del electorado a nivel nacional y traslademos a esas personas procedentes de todo el país a un mismo lugar. Introduzcamos a la muestra en las cuestiones a tratar, con informes cuidadosamente equilibrados, con discusiones intensivas en pequeños grupos y démosle la oportunidad de preguntar a políticos y expertos con distintas opiniones. Después de varios días de trabajo cara a cara, encuestemos a los participantes en detalle. La encuesta resultante ofrece 
una representación de las opiniones del público." Mientras que las encuestas tradicionales consisten solamente en una "agregación estadística de vagas impresiones formadas, en su mayor parte, en la ignorancia de argumentos considerablemente contrapuestos", las encuestas deliberativas nos permiten conocer "lo que el público pensaría si tuviera mejores oportunidades para evaluar los problemas en cuestión”.

Los dispositivos deliberativos que reúnen a ciudadanos comunes pueden tener ventajas epistemológicas sobre el gobierno representativo y los comités de sabios: la buena deliberación debe incluir diversos puntos de vista, de manera que el abanico de argumentos considerados sea más amplio y la discusión más inclusiva (Landemore, 2012; Elster, 2013). Desde esta perspectiva, los mini-públicos seleccionados aleatoriamente tienen la ventaja de ser socialmente $-\mathrm{y}$, por tanto, epistemológicamente - más ricos que los comités de expertos o de líderes políticos; también son social y epistemológicamente más ricos que los espacios donde los participantes proceden únicamente de voluntarios o de la sociedad civil ya organizada. Además, en relación a la creación de "élites" basadas en ciertas características socio-económicas, la muestra aleatoria es una herramienta muy potente para evitar el sesgo de auto-selección que desvirtúa otros experimentos democráticos basados en la participación voluntaria.

La lógica de los mini-públicos seleccionados aleatoriamente es, por tanto, muy específica. Gordon Gibson (2007), el creador de la Asamblea Ciudadana de la Columbia Británica y consejero del Primer Ministro, justificó así su iniciativa:

"Estamos... añadiendo nuevos elementos tanto a la democracia representativa como a la directa. Estos nuevos elementos varían en su detalle, pero tienen una cosa en común. Añaden a la mezcla un nuevo tipo de representantes, diferentes de los que elegimos. Actualmente, los dos canales de toma de decisiones están enormemente influenciados - casi secuestrados - por expertos e intereses particulares. La idea de la democracia deliberativa consiste básicamente en introducir el interés público, representado aleatoriamente, como una potente tercera vía. Los representantes tradicionales que elegimos lo son por consenso mayoritario, durante un período prolongado, como profesionales con competencias ilimitadas para actuar en nuestro nombre. Los representantes de nuevo cuño de los que hablamos se eligen por sorteo, por un corto período de tiempo, como ciudadanos comunes con un propósito específico y limitado".

Esto plantea una tensión entre la deliberación por parte de los mini-públicos y la deliberación por parte de las masas. Por definición, los mini-públicos deliberativos aspiran a lograr una opinión contrafactual de lo que la opinión pública podría ser - están mejor informados y disfrutan de un entorno razonablemente satisfactorio en el que esta opinión puede formularse - . Pero esta opinión puede perfectamente diferir de la opinión pública más extensa. Deliberación y participación pueden ser presentadas como dos modelos opuestos de democracia (Held, 2006). No tiene por qué ser así, pero las contrapartidas son inevitables y siempre habrá quienes privilegien la lógica de la participación sin restricciones sobre la deliberación y viceversa (Sintomer, 2011b). La relación entre la opinión 
deliberativa de los mini-públicos y la opinión pública a gran escala es, en cualquier caso, un gran problema político y teórico. Además, los ciudadanos seleccionados aleatoriamente son separados de sus contextos sociales previos y situados juntos artificialmente. Los mini-públicos, por lo tanto, se diferencian de otros experimentos democráticos, como los presupuestos participativos, que están más integrados en las relaciones sociales y políticas cotidianas. Frecuentemente, los mini-públicos suelen ser más experimentales que influyentes: la gran mayoría no ha producido cambios sustanciales en el mundo real -aunque puedan tener otro tipo de impactos (Goodin y Dryzek, 2006). Dado que su existencia depende exclusivamente de la voluntad de las autoridades públicas, es poco probable que realmente puedan ser subversivos respecto a las estructuras de poder. En el peor de los escenarios, la deliberación democrática de un pequeño círculo de ciudadanos seleccionados aleatoriamente podría sustituir a una democracia deliberativa que incluyera a todos los ciudadanos (Chambers, 2009). En tales circunstancias, los mini-públicos deliberativos constituirían un tipo de elitismo que argumentaría que la implicación de los ciudadanos comunes en política solo puede tener lugar dentro del espacio controlado de los minipúblicos, mientras que otras formas de participación serían sospechosas de introducir elementos emocionales y no racionales.

\subsection{Sorteo y política: una tipología}

Por tanto, parece que aunque existen los paralelismos entre la democracia ateniense y los modernos mini-públicos deliberativos, no deberían sobreestimarse. Recuperando la noción elaborada por Tomás de Aquino, estamos enfrentándonos en ambos casos a un sorteo distributivo, pero las dos formas se derivan de lógicas opuestas. Antes de concluir, las examinaremos en un contexto más amplio que permite una lectura comparativa históricosociológica del significado político de seleccionar cargos públicos por sorteo.

El sorteo puede emplearse ya sea en exclusiva o combinado con otros métodos. Solamente después del triunfo del gobierno representativo a finales del siglo XVIII se han usado exclusivamente la elección o la cooptación (en los nombramientos ministeriales, por ejemplo) para seleccionar cargos políticos, mientras que los altos puestos de la administración estatal se han asignado mediante concurso público o cooptación por los superiores. Durante mucho tiempo, la selección por sorteo fue una de las maneras más extendidas de proveer tales cargos en los sistemas republicanos y democráticos. No obstante, sería erróneo interpretar el uso político del sorteo de manera reduccionista, unilateral, ya sea como una parte inseparable de la "verdadera democracia" o como un dispositivo cuya esencia consiste en la resolución imparcial de conflictos (Dowlen, 2008; Buchstein, 2009). El análisis sociológico e histórico muestra que la selección aleatoria puede derivarse de lógicas políticas bastante diferentes. Si bien estas pueden perfectamente combinarse en la práctica, es posible distinguir cinco grandes tipos-ideales de cara al análisis, creando una segunda tipología que es transversal a la trilogía sorteo distributivo, sorteo adivinatorio y juegos de azar.

1. Adivinación. El sorteo puede tener una interpretación religiosa o sobrenatural y, en particular, puede leerse como una señal divina. La Biblia describe claramente 
este uso de la selección aleatoria: "La suerte se echa en el regazo, pero del Señor viene toda decisión" (Proverbios, 16, 33). Desde esta perspectiva, para gestionar los asuntos comunes, los seres humanos deben seguir la voluntad divina o las señales de un destino que resulta inaccesible de cualquier otra manera. La sors divisoria está intrínsecamente ligada a la sors divinatoria. Aunque es posible que el sorteo político tuviera orígenes religiosos, esos orígenes fueron, en el mejor de los casos, de una importancia marginal en la Atenas clásica y son igualmente irrelevantes en la democracia deliberativa contemporánea.

2. Imparcialidad. La selección aleatoria puede también pensarse como un medio imparcial para resolver una cuestión en disputa. Uno de los proverbios salomónicos lo expresa sucintamente: "La suerte pone fin a las contiendas y decide entre los poderosos" (Proverbios, 18, 18). Esta lógica estuvo muy extendida a lo largo de la historia, pero también puede interpretarse de distintas maneras. La imparcialidad puede asociarse a la naturaleza del procedimiento (cómo ocurre la selección), pero también a su insumo (quién es seleccionado) y al tipo de deliberación que hace posible.

3. Autogobierno, democracia radical. La selección por sorteo asociada a la rápida rotación de los cargos también puede verse como un procedimiento que favorece el autogobierno de todos por todos, en el que cualquiera gobierna y es gobernado por turnos. Esto significa que las tareas de gobierno ya no se confían a "los mejores", a una élite social o a políticos profesionales. Los tipos de autogobierno e igualdad en cuestión varían de acuerdo a la naturaleza del grupo a partir del cual se hace el sorteo. Cuando el grupo es socialmente heterogéneo, el sorteo es una herramienta poderosa para combatir la distinción social, constituyendo así el método democrático por excelencia. Este elemento fue central en Atenas y supuso una dimensión clave de su democracia radical.

4. El sentido común de los ciudadanos de a pie. Desde otra perspectiva, el sorteo puede verse como una garantía para que cualquiera pueda acceder el poder: es decir, para que el poder puedan ejercerlo individuos que son intercambiables con otros porque todos se basan en su "sentido común". Esta concepción se desarrolló principalmente en relación a los jurados judiciales, donde la definición de "cualquiera" puede variar considerablemente y algunos pueden ser considerados "más iguales que otros". Este razonamiento no era ajeno a las prácticas atenienses y aún se encuentra, aunque de manera un tanto atenuada, en los procedimientos contemporáneos.

5. Democracia deliberativa. Lo que distingue a los mini-públicos deliberativos es que consideran a la selección por sorteo principalmente como un medio para lograr una muestra representativa (o al menos una sección razonablemente diversificada) del pueblo. Este mini-público contrafactual es capaz de formular opiniones, evaluar, juzgar y quizás incluso decidir en nombre de la comunidad, cuando no es posible que todos participen en las deliberaciones y la idea de que todos los individuos son intercambiables se descarta a causa de la heterogeneidad social. Esta perspectiva, que presupone el concepto de muestra representativa, se desarrolló tardíamente en la historia. 
Figura 2: Las racionalidades políticas del sorteo

\begin{tabular}{|c|c|c|c|c|}
\hline Adivinación & Imparcialidad & $\begin{array}{c}\text { Auto-gobierno, } \\
\text { democracia } \\
\text { radical }\end{array}$ & $\begin{array}{c}\text { El sentido } \\
\text { común de los } \\
\text { ciudadanos de } \\
\text { a pie }\end{array}$ & $\begin{array}{c}\text { Democracia } \\
\text { deliberativa }\end{array}$ \\
\hline $\begin{array}{c}\text { Conocer el } \\
\text { destino / la } \\
\text { voluntad } \\
\text { divina }\end{array}$ & $\begin{array}{c}\text { Resolver de } \\
\text { manera neutral } \\
\text { las disputas } \\
\text { entre individuos } \\
\text { poderosos y/o } \\
\text { facciones }\end{array}$ & $\begin{array}{c}\text { Permitir el auto- } \\
\text { gobierno, según } \\
\text { la fórmula } \\
\text { mediante la } \\
\text { cual "todos } \\
\text { gobiernan y son } \\
\text { gobernados por } \\
\text { turnos" }\end{array}$ & $\begin{array}{c}\text { Basarse en el } \\
\text { sentido común } \\
\text { general para } \\
\text { encontrar } \\
\text { soluciones } \\
\text { para problemas } \\
\text { específicos }\end{array}$ & $\begin{array}{c}\text { Posibilitar que } \\
\text { una muestra } \\
\text { representativa } \\
\text { o una sección } \\
\text { razonablemente } \\
\text { diversificada del } \\
\text { pueblo delibere } \\
\text { en condiciones } \\
\text { óptimas }\end{array}$ \\
& & & & \\
\hline
\end{tabular}

Fuente: compilada por el autor.

\section{Conclusión}

Muchos defensores contemporáneos del sorteo en política reivindican el legado ateniense, argumentando que el sorteo fue parte integrante de la invención de la democracia occidental. Las referencias a Atenas juegan un rol importante en las experiencias contemporáneas. Sin embargo, esas pretensiones deben matizarse a la luz de las comparaciones históricas y teóricas. Combinado con la rápida rotación de los cargos, el sorteo político fue fundamental en el Ática durante el período clásico de la Antigua Grecia. Ambos fueron componentes de un autogobierno real que suponía una dimensión central del ideal de la democracia radical y ayudaron a convertir a Atenas y a otras polis griegas democráticas en ejemplos únicos en el mundo antiguo: la sors divisoria fue fundamental allí, mientras que fue marginal en el resto del mundo. Al revés, la sors divinatoria, muy extendida en la época, no tuvo influencia real sobre el sorteo político en la Atenas clásica. Los mecanismos contemporáneos basados en la selección aleatoria han dependido del concepto de muestra representativa, desconocido antes de finales del siglo XIX. Estos mini-públicos representan una opinión contrafactual - lo que el gran público podría pensar si realmente pudiera deliberar. Por tanto, están estrechamente vinculados al ideal de la democracia deliberativa, considerablemente diferente al de la democracia radical ateniense. Esta comparación puede extenderse a una tipología más general, donde la democracia radical y la democracia deliberativa son solamente dos de los cinco modelos del sorteo político.

Uno de los principales retos que deben enfrentar los mini-públicos deliberativos seleccionados aleatoriamente consiste en que la opinión "ilustrada" que posibilitan no solamente tiende a diferir de la opinión pública general, sino que de hecho puede ser instrumentalizada en contra de ella - algo que era inconcebible en Atenas. Además, los mini-públicos, en una primera etapa (jurados de ciudadanos, conferencias de consenso, sondeos deliberativos), 
han sido instrumentos desde arriba, dependientes de la buena voluntad de las autoridades políticas, por lo que difícilmente pueden provocar cambios sustanciales en el mundo real. No obstante, aunque su lógica intrínseca es diferente de la ateniense, podrían adquirir relevancia nuevamente combinados con otros procedimientos y procesos sociales. Asimismo, podrían suponer una fuente de legitimidad compatible - antes que opuesta - con la legitimidad de la democracia representativa o la democracia directa. En definitiva, podrían contribuir a la pluralización de las formas de legitimidad democrática (Rosanvallon, 2006).

Numerosos estudiosos y practicantes, a menudo pensando en Atenas, han investigado cómo sus normas deliberativas casi ideales podrían combinarse con un discurso más inclusivo y heterogéneo en una esfera pública más amplia. Esto ha llevado a experiencias a gran escala, como aquellas que combinan Asambleas Ciudadanas y referéndum o como la Revisión de la Iniciativa Ciudadana (Citizens' Initiative Review) en Oregón. En esta segunda etapa de experimentación, que ha crecido en la década de 2010, el sorteo está asociado, una vez más, con decisiones hechas directamente por el conjunto de los ciudadanos, como ocurría en la mayoría de las experiencias republicanas y democráticas a lo largo de la historia. La democracia deliberativa está articulada a la democracia participativa y a la democracia directa, así como a transformaciones democráticas de la democracia representativa (Sintomer, 2018). Para que esta innovación sea verdaderamente significativa, debe institucionalizarse legalmente y no depender exclusivamente de la voluntad de líderes políticos. En el siglo XXI, podría perfectamente ocurrir que los antiguos ideales y prácticas de la democracia ateniense experimentaran un renacimiento. No se trata de eliminar las elecciones, sino de enriquecer las dinámicas de la democracia incorporando este nuevo elemento a gran escala. Sería ingenuo pensar que la política simplemente seguirá como hasta ahora, con pequeños cambios en comparación con el siglo anterior. Dadas las dimensiones de la reciente crisis financiera, el cada vez más grave estancamiento del actual modelo productivo y el descrédito masivo en que ha caído la política institucional, preservar el statu quo no es realista ni conveniente.

\section{Referencias}

Adams, J. (1851): “Letter to John Penn," en The Works of John Adams, vol. 4 (Novanglus, Thoughts on Government, Defence of the Constitution), Charles C. Little and James Brown, Boston.

Abramson, J.B. (2003): We The Jury. The Jury System and the Ideal of Democracy, 3rd edn., Harvard University Press, Cambridge (Mass.)/Londres.

Aquino, T. (2008): “Les sorts (1270-1271)," en L'astrologie. Les opérations cachées de la nature. Les sorts, Les Belles Lettres, París.

Aristóteles (1962): The Politics, Penguin, Harmondsworth.

Aristóteles (1984): The Athenian Constitution, Penguin, Harmondsworth.

Buchstein, H. (2009): Demokratie und Lotterie, Campus, Frankfurt/Main.

Cardano, F., Grottanelli, C. (coord.) (2011): Sorteggio Pubblico e Cleromanzia dall'Antichità all'Età Moderna, Et, Milán.

Carson, L., Martin, B. (1999): Random Selection in Politics, Praeger Publishers, Westport. Castoriadis Cornélius (1986): Domaines de l'homme, Seuil, París. 
Chambers, S. (2009): "Rhetoric and the Public Sphere: Has Deliberative Democracy Abandoned Mass Democracy?", Political Theory, 37, pp. 323-350.

Coleman Stephen, Przybylska Anna, Sintomer Yves (coord.) (2015): Deliberation: values, processes, institutions, Peter Lang, Frankfurt/Main.

Crosby, N. (1975): In Search of the Competent Citizen, Center for New Democratic Processes, Plymouth.

Demont, P. (2000): "Lots héroïques : remarques sur le tirage au sort de l'Iliade aux Sept contre Thèbes", Revue des Études Grecques, 113, pp. 299-325.

Dienel, P. (1997): Die Planungszelle, Westdeutscher Verlag, Wiesbaden.

Dowlen, O. (2008): The Political Potential of Sortition. A Study of the Random Selection of Citizens for Public Offices, Imprint Academic, Exeter (UK)/Charlottesville (USA).

Dryzek, J. (1990): Discursive Democracy. Politics, Policy and Political Science, Cambridge University Press, Cambridge.

Elster, J. (ed) (1998): Deliberative Democracy, Cambridge University Press, Cambridge.

Elster, J. (2013): Securities Against Misrule. Juries, Assemblies, Elections, Cambridge University Press, Cambridge.

Finley, M. I. (1991): The Invention of Politics, Cambridge University Press, Cambridge.

Fishkin, J. (1997): The Voice of the People. Public Opinion \& Democracy, Yale University Press, New Haven/Londres.

Fishkin, J. (2015): "Reviving Deliberative Democracy: Reflections on Recent Experiments," en Coleman, Przybylska y Sintomer (coord.): Deliberation: values, processes, institutions, Peter Lang, Frankfurt/Main, pp. 99-108.

Gibson, G. (2007): "Deliberative Democracy and the B.C. Citizens' Assembly," http:// www.ccfd.ca/index.php?option=com_content $\&$ task=view\&id=409\&Itemid=284 (Citizens Centre for Freedom and Democracy), 02/23/2007, última consulta el 22/12/2015.

Goodin, R. E. y Dryzeck, J. (2006): “Deliberative Impacts: The Macro-Political Uptake of Mini-Publics", Politics and Society, 34, pp. 219-244.

Guidorizzi, G. (2001): “Aspetti mitici del sorteggio," en Cardano y Grottanelli (coord.): Sorteggio Pubblico e Cleromanzia dall'Antichità all'Età Moderna, Et, Milán, pp. 41-54.

Habermas, J. (1996): Between Facts and Norms: Contributions to a Discourse Theory of Law and Democracy, MIT Press, Cambridge (MA).

Hacking, I. (1990): The Taming of Chance, Cambridge University Press, Cambridge.

Hansen, M.H. (1991): Athenian Democracy in the Age of Demosthenes, Basil Blackwell, Oxford.

Held, D. (2006): Models of Democracy, 3rd edn., Polity Press, Cambridge.

Homero (1998): The Iliad, Penguin.

Homero (2006): The Odyssey, Penguin.

Knobloch, K. R., Gastil, J. y Reitman, T. (2015): “Connecting Micro-Deliberation to Electoral Decision Making: Institutionalizing the Oregon Citizens' Initiative Review," en Coleman, Przybylska y Sintomer (coord.): Deliberation: values, processes, institutions, Peter Lang, Frankfurt/Main, pp. 21-40.

Landemore, H. (2012): Democratic Reason: Politics, Collective Intelligence, and the Rule of the Many, Princeton University Press, Princeton. 
López-Rabatel, L. (1991): Kleroteria. Le tirage au sort dans le monde grec antique: Machines institutionnelles et usages, Université de Lyon 2, PhD, Lyon.

Manin, B. (1997): Principles of Representative Government, Cambridge University Press, Cambridge.

Mirabeau (1789): "Discours devant les états de Provence," en CEuvres de Mirabeau (1825), VII:7, citado en Rosanvallon (1998): Le peuple introuvable. Histoire de la représentation démocratique en France, Gallimard, París.

Pitkin, H. (1972): The Concept of Representation, University of California Press, Berkeley/ Los Ángeles.

Rancière, J. (2009): Hatred of Democracy, Verso, Londres.

Rosanvallon, P. (1998): Le peuple introuvable. Histoire de la représentation démocratique en France, Gallimard, París.

Rosanvallon, P. (2006): La contre-démocratie, Seuil, París.

Ruzé, F. (1997): Délibération et pouvoir dans la cité grecque de Nestor à Socrate, Publications de la Sorbonne, París.

Sintomer, Y. (2011a): Petite histoire de l'expérimentation démocratique. Tirage au sort et politique d'Athènes à nos jours, La Découverte, coll. Poches, París.

Sintomer, Y. (2011b): "Délibération et participation: affinité élective ou concepts en tension)", Participations. Revue de sciences sociales sur la démocratie et la citoyenneté, 1, pp. 239-276.

Sintomer, Y. (2018): "From deliberative to radical democracy? Sortition and politics in the 21th century", en J. Gastil, E. O. Wright (coord.): Legislature by Lot. An Alternative Design for Deliberative Governance, Verso, Londres/Nueva York.

Stone, P. (2009): “The Logic of Random Selection”, Political Theory, 37, pp. 375-397.

Tucídides (1900): The Peloponnesian War, traducido al inglés por Benjamin Jowett. Second edition, Clarendon Press, Oxford.

Villacèque, N. (2013): Spectateurs de paroles! Délibération démocratique et théâtre à Athènes à l'époque classique, PUR, Rennes.

Waren, M. E. y Pearse, H. (2008) (coord.): Designing Deliberative Democracy. The British Columbia Citizens' Assembly, Cambridge University Press, Cambridge (MA). 
